Original Research

\title{
Factors Correlated to Job Stress Among ICU Nurses
}

\author{
Yulis Setiya Dewi ${ }^{1}$, Rachmat Hargono ${ }^{2}$ and Ainur Rusdi ${ }^{3}$ \\ ${ }^{1}$ Faculty of Nursing, Universitas Airlangga, East Java, Indonesia \\ 2 Faculty of Public Health, Universitas Airlangga, East Java, Indonesia \\ ${ }^{3}$ Soetomo General Hospital, East Java, Indonesia
}

\begin{abstract}
Introduction: Job stress is a major barrier to the attainment of safety, health, and wellness among nurses. Understanding factors job stress among nurses is very important to provide alternatives solution to ease the stress in the future. However, there are limited studies with respect to factors related to stress in Intensive Care Unit (ICU) nurses particularly in Indonesian context. This study aimed to identify factors correlated to job stress among ICU nurse in three public hospitals.
\end{abstract}

Methods: A correlational study was carried on ICU nurses who hands-on ICU nursing care. Data were collected using questionnaires. Descriptive statistic and Spearman correlation were used to analyze the correlation between perceived job burden, working condition, quality of nursing work life, perceived organizational support, and stress among ICU nurses.

Results: A total of 91 respondents (32 male and 59 female) were involved to the study comprises of two different educational backgrounds (59 Diploma III and 32 Bachelor degree). The statistical analysis using Pearson correlation found that workload (0.003), working condition $(0.000)$, quality of nursing work life $(0.000)$, perceived organizational support (0.000) significantly correlated to job stress among ICU nurses.

Conclusion: All studied factors correlated to job stress among ICU nurses. All factors had moderate correlation with nurses' job stress and working condition has highest strong correlation compare to the other factors. Its implies from the result that management of the hospital may provide more attention to job stress among nurses to maintain optimum performance to provide nursing care for patients particularly critically ill patients in ICU.

\section{ARTICLE HISTORY}

Received: Feb 25, 2019

Accepted: May 12, 2019

\section{KEYWORDS}

ICU; job stress; nurses; QNWL; organisational support; working condition, workload

\section{CONTACT}

\section{Yulis Setiya Dewi \\ $\triangle$ yulis.sd@fkp.unair.ac.id $\equiv$ Faculty of Nursing,} Universitas Airlangga, East Java, Indonesia

Cite this as: Dewi, Y.S., Hargono, R., \& Rusdi, A. (2019). Factors Correlated to Job Stress Among ICU Nurses in Surabaya Indonesia. Jurnal Ners, 14(1),23-27. doi:http://dx.doi.org/10.20473/in.v14i1.12125

\section{INTRODUCTION}

The ICU nurses are confronted with the unpleasant facts every day and it is very difficult to avoid the source of stress. On the other hand nurses are required to always perform caring behaviour not only for patients but also for the patient's family. Previous studies revealed major stressor among ICU nurses include consistent contact with dying, interaction between patients' and family members, conflict with supervisors, uncertain condition and health progress of patients (Burtson and Stichler, 2010; Sarafis et al., 2016). Research in one hospital in East Java found that there was a relationship between job stress and caring behaviour where nurses did not provide caring behaviour optimally (74\%) because they experienced stress at moderate and severe levels (Desima, 2013). While other studies at the Intensive Care Unit showed that nurses indicate stressful behaviour (43.1\%), experienced physical stress (43.7\%), and experienced emotional stress (46.7\%) (Amiyanti, 2000). A study found that Critical Care nurses experience greater level of stress compare to Internal Surgical Unit in Tehran (Zaher, Vafaei and Abianeh, 2016). Consistent contact with the events of death, interactions with patients and their families, conflicts with supervisors and uncertainty about therapy caused much higher stress in ICU nurses (Burtson and Stichler, 2010; Sarafis et al., 2016)

The characteristics of the ICU and the high need for care can cause stress-related symptoms, namely Post-Traumatic Stress Disorder (PTSD), anxiety, 
depression and burnout syndrome (Cavalheiro, Moura Junior and Lopes, 2008; Mealer et al., 2012, 2018; Zhang, Huang and Guan, 2014; Siffleet et al., 2015). All the problems faced drain the energy, mind, concentration, physical and psychological health conditions of the nurse in various forms, for example being cynical and indifferent to patients, often ditching, often feeling dizzy, wanting to always change their jobs, and apathy towards the future of themselves. The results of the preliminary study through unstructured interviews in March 2018 with the head of the Intensive Care Unit and Reanimation in one of the government hospitals in Surabaya were in 2010 found that $34 \%$ of nurses requested for job rotation to another ward. In the period JanuaryMarch 2018, there were 4 people (out of 44 ICU nurse) who asking for job rotation to other wards due to many factors including health issues. Stress may cause more severe psychological problems and this can have an impact on nurses' interactions with other health workers, nurses' jobs performance, and institution's reputation (Mariani, 2013).

It is important to understand factors correlated to nurses' stressors in ICU including perceived job burden, working condition, quality of nursing work life, perceived organizational support. This result may provide a solution for the nurse manager to ease level of stress among ICU Nurses.

\section{MATERIALS AND METHODS}

\section{Research Design}

This study is a part of bigger study conducted by researcher and become preliminary steps for constructing a model to develop resilience model. A correlational design was used to reveal relationship between job stress including quality of nursing worklife, job burden, and stress among ICU nurses. The factors were namely perceived job burden, working condition, quality of nursing work life, perceived organizational support were identified to correlated with stress of ICU nurses. This study conducted at Soetomo General Hospital, Universitas Airlangga Teaching Hospital, and Hajj General Hospital Surabaya, East Java, Indonesia.

\section{Respondents}

The respondents were recruited from three different hospitals using total population sampling method. The population included all staff nurses. This means that all nurses were involved to the study but not with those who in managerial level such as nurse unit manager and nurse unit coordinator. A total of 95 nurses were voluntary participated to the study but only 91 nurses completed all questionnaires. Those who did not fill in the questionnaire completely considered as drop out from the study.

\section{Measurement tools}

The data collection tools were single questionnaires on socio-demographic characteristic were designed by researcher. In addition, the questionnaires for all variables were adopted from existing questionnaire. Researcher made some adjustment on the questionnaire and tested the validity and reliability of the questionnaires on April, 15 - May 3, 2018 to 26 at ICU Nurses in Darmo Hospital, Surabaya. Validity test was using Pearson product-moment with coefficient correlation $>0.5$. Item no 13 on working condition tool was not considered valid. Researcher made modification on the sentence structure and diction to make it readable since this is an important question. Tools on perceived job burden, working condition, job stress and QNWL were considered reliable with result $0.936,0.819,0.732$ and 0.840 respectively after tested using Alfa Cronbach. However tool for perceived organisational support was not reliable. Researcher reviewed and made modification before it was used. Translation was accomplished by researcher and proofread by Journal Development Team from Faculty of Nursing, Universitas Airlangga, Surabaya Indonesia.

Measurement tools to explore demographic data was developed by researcher based on current characteristic of nurses in public hospital in Surabaya. The demographic data included ages, work experience, gender, and level of education. Tools for job stress was adopted form Nursing job stress questionnaire from Nursalam (2015) consisted of 30 items. Likert scale was occupied using 4 scales from always to never choices. Tools for nursing workload was also adopted from Nursalam (2015) which is consisted of 12 question and using Likert scales with 4 scales from always to never choices. In addition for QNWL (Quality of Nursing Work Life was adopted from Brook (2001, cited from (Nursalam, 2015)) consisted of 42 statements and the chosen answers used Likert scales from very agree to very disagree. Organizational support questionnaire was adopted from Perceived Organizational Support (Eisenberger and Huntington, 1996) using Likert scale with very agree to very disagree choices for 25 statements.

\section{Data Collection}

Data was collected at July-September 2018. A questionnaire was completed with description of the study, consent procedure, response confidentiality and researcher's contact details. The questioner was completed independently by the respondents and collected by researcher in the same day. It took about two months to reached all respondents from three different hospitals and due to shift schedule and administrative process in the hospitals .

\section{Data Analysis}

Original data were inputted into excel spreadsheet and checked by researcher. All data were analyzed using the SPSS 20.00 software. Descriptive Analysis included frequency, percentages, means and standard deviation were used to provide descriptive data. Data was analysed using Pearson correlation to identify the influence between workload, working condition, 
Table 1. Sociodemographic characteristic of respondents $(\mathrm{n}=91)$

\begin{tabular}{lcc}
\hline \multicolumn{1}{c}{ Variable } & $\mathbf{n}$ & $\mathbf{\%}$ \\
\hline Age (years) & 3 & \\
$<25$ & 35 & 3.3 \\
$25-30$ & 19 & 38.5 \\
$31-35$ & 8 & 20.9 \\
$36-40$ & 14 & 8.8 \\
$41-45$ & 6 & 15.4 \\
$46-50$ & 6 & 6.6 \\
$51-55$ & 6.6 \\
Work Experience (yrs) & 7 & \\
$<1$ & 37 & 7.7 \\
$1-5$ & 19 & 40.7 \\
$6-10$ & 9 & 20.9 \\
$11-15$ & 11 & 9.9 \\
$16-20$ & 5 & 12.1 \\
$21-25$ & 3 & 5.5 \\
$26-30$ & & 3.3 \\
Sex & 32 & 35.2 \\
Male & 59 & 64.8 \\
Female & & \\
Level of Education & 59 & 64.8 \\
Diploma 3 & 32 & 35.2 \\
Bachelor & &
\end{tabular}

Table 2. Description of Independent and Dependent Variables

\begin{tabular}{lcc}
\hline \multicolumn{1}{c}{ Variable } & Mean & SD \\
\hline Independent & & \\
Perceived Job Burden & 27.87 & 7.627 \\
Working Condition & 43.31 & 7.034 \\
QNWL & 146.48 & 17.363 \\
Working Support & 69.36 & 7.531 \\
Dependent & & \\
Physical stress & 32.29 & 4.483 \\
Psychological stress & 60.94 & 7.625 \\
Job Stress & 93.24 & 11.33 \\
\hline
\end{tabular}

Table 3. Correlation of Job Stress Among ICU nurses (Pearson's Correlation)

\begin{tabular}{lcc}
\hline \multirow{1}{*}{ Variable } & \multicolumn{2}{c}{ Job Stress of ICU Nurses } \\
\cline { 2 - 3 } & $\mathbf{r}$ & p-value \\
\hline Perceived Job Burden & 0.310 & 0.003 \\
Working Condition & 0.432 & 0.000 \\
QNWL & 0.389 & 0.000 \\
Perceived & 0.420 & 0.000 \\
Organisational Support & & \\
\hline
\end{tabular}

quality of nursing work life, perceived organizational support, and stress among ICU nurses. In this study the statistical level of significance was set at $\mathrm{p}<0.05$ for two sides.

\section{Ethical Consideration}

Ethical approval was obtained from the ethic committee of the three hospitals i.e Dr. Soetomo Hospital (No. 0325/KEPK/V2018), Hajj General Hospital (No. 073/11/KOM.ETIK/2018) dan Universitas Airlangga teaching hospital (No. 145/KEH/2018). Voluntary, confidentially, fair and harmless ethical principles were occupied in this study. We explained carefully the purpose, benefits and risk to the respondents before they asked to participate to our study. All respondents who agree to involved in the study had been asked to sign the written informed consent freely. Respondent received tea set as a reward from researcher for their time and willing to participate to the study.

\section{Significance of the study}

Job stress can lead to an important impact on individual ICU nurses and their activities such as lack of concentration, decrease job motivation, emotionally vulnerable to patients and conflict with other health care worker. This situation may impair their job performance, decrease their job satisfaction and leads to medication errors. Thus, it is important to identify factors may correlated to job stress among ICU nurses.

\section{RESULTS}

\section{Sociodemographic characteristic of respondents}

A total of 95 questionnaires were distributed but 91 were completed and the rest was considered incomplete and invalid therefore indicating 94,8\% returned rate. The majority of the respondent age at the range of $23-54$ years. Level of education was dominated at D3 level $(64,8 \%)$ with work experience at $1-5$ yrs $(40.7 \%)$. A total of $64.8 \%$ was female nurses. Table 1 provide the other demographic data of the respondents.

\section{Characteristic of Respondents}

The characteristic of respondent described in the table 1 . The vast majority of respondent were between 25-35 years old. Most of the respondents had work experience under 10 years where $37 \%$ were under 5 years. Female were dominant staff compare to male staff. Respondents were mostly had diploma degree and none of them were graduated from post graduate degree and above.

\section{Variable description}

All variables of the study have been stated in the Table 2. The averages perceived job burden was 27,86 ( $S D=7.62)$. The working condition was in the average of 43.30 ( $\mathrm{SD}=7.034$ ) where as quality of nursing work life was in the average of 146.48 ( $S D=17.36$ ). Organisational support has been perceived by the ICU nurse was an average of 69.36 (SD=7.531). The total average job stress among ICU nurses reached 93.24 ( $\mathrm{SD}=11.33)$ as provided in table 3 .

All variables of the study have been stated in the Table 2. The averages perceived job burden was $27,86(\mathrm{SD}=7.62)$. The working condition was in the average of $43.30(\mathrm{SD}=7.034)$ where as quality of nursing work life was in the average of 146.48 ( $S D=17.36)$. Organisational support has been perceived by the ICU nurse was an average of 69.36 ( $S D=7.531$ ). The average job stress among ICU nurses reached $93.24(\mathrm{SD}=11.33)$. 


\section{DISCUSSION}

Correlation between job stress and variables was analyzed using Pearson's correlation. The result showed that there was correlation between perceived job burden, working condition, QNWL and perceived support and nursing job stress.

\section{Perceived Job Burden}

Perceived job burden correlated with job stress among ICU nurses. This result is in line with previous study in Pakistan (Johan, Sarwar and Majeed, 2017) that job burden correlated with kind of stress among ICU nurses. Intensive care unit is considered as a high demand of care where nurses have to provide total care using sophisticated equipment such as ventilator, continuous renal replacement therapy infusion pump, syringe pump, portable X-ray and a lot of life-saving tools and medicines. This situation need more concentration and extra energy from nurses. In addition, in three public hospital in Surabaya, the ratio between nurse and patients is remain inappropriate to the standard in which based on observation of researcher frequently 2 nurses have to handle 3-4 ventilated patients. According to Ministry of Health of Indonesia (2006) ratio nurse - patient for ventilated patients is $1: 1$ and 1: 2 for unventilated patients. However, in this three hospital this ideal ratio was difficult to apply due to nursing shortages in each hospital particularly in Soetomo Hospital. Soetomo Hospital provides tertiary ICU care and as referral hospital in eastern part of Indonesia. Meanwhile, from the researcher observation, nurse also had to handle other administrative task such as patient's billing, and etc. As the consequence, nurse workload was high and correlated with level of stress.

\section{Working condition}

Working condition was correlated with job stress among ICU nurses. It has been known that working in ICU it takes a thoughtful task, quick thinking, and dedication to achieve the advanced skills necessary for the job. Handling difficult patients is a frequent cause of stress for ICU nurses (Vahedian-azimi et al., 2017). The results of this study support previous studies that work conditions are related to the stress level of ICU nurses (Andolhe et al., 2016). In Surabaya, unpleasant working condition in ICU may include alarms, restricted area, sophisticated machines which may not all nurses able to operate, fluid body secretion, limited time to communicate with other staff and health care worker, un-cooperative patient's relatives, unstable and unpredicted situation. In this study, most of nurses had work experience at under 10 years (more than $69.2 \%$ ) and under 5 years $(37 \%)$ and they still in the journey of mastering all equipment which is not easy and may find it difficult to adapt with. Some of the nurses were also still learn about such procedures and also may not confidence to communicate with patients' family and other health care professional, especially those who experienced under 1 year.

\section{Quality of nursing work life}

Quality of nursing work life correlated to job stress of ICU nurses. This result was in accordance with present study that there was a correlation between job stress and QNWL (Roshangar et al., 2017). It has been widely accepted that staff nurse are challenging with relatively stressful work environment including irregular scheduling or shifting and socio-emotional pressures related to the patients and their own family almost every day (Jaafarpour, Khani and Mahmodian, 2015). In addition, due to the complex nature of working in critical care, nurses in the ICU encounter more pressure and stress than general ward nurse. This situation may be worsen when the nurse relates the distress from a patient's situation with one in his/her own personal life. Furthermore another study found that Nurse's high work pressure declines QWL. Thus, nurses often are deprived of energy and are not able to stabilize their work life and family life (Roshangar et al., 2017). Based on the characteristic of respondents of this study, the majority $(59,4 \%)$ of them are in the productive ages (25-35 year old) where they are just starting a family and busy with domestic chores and taking care of their children. It could be understood that nurses are still struggling to balancing between working-life and personal-life.

\section{Perceived organizational support}

This study revealed that there was correlation between perceived organizational support and nursing job stress. This result was in the contrary with recent study that there was a negative relationship between nurses' job stress and organizational support (Roshangar et al., 2017). This different result may be due to different participant of the study. This study was for ICU nurses whereas another study conducted for all type of nurses. However, a research found that there was correlation between organizational support and job stress among nurses at Saudi Public Hospital (Al-homayan et al., 2013). The study also confirmed that nurses who received organizational support performed a better job than being stressed at work by mitigating the effect of job stress on job performance (Al-homayan et al., 2013). ICU nurses who provide total care for critically ill patients have to adapt to a fast-paced and stressful environment by functioning within their own culture. Therefore organizational support is needed to keep nurses work on their best performance and lighten adversity in the workplace.

\section{CONCLUSION}

The result of this study revealed that most of the participant had work experience less than 10 years and most of them were at the age of under 35 years. There were significant correlation between workload, working condition, QNWL and perceived 
support and nursing job stress. Based on the study result, it is important for the management of hospital to provide more attention on the nurses' psychological and personal aspect to help them bounce back from difficult situation in the workplace. Such of education or training is required to help nurses adapt with difficult situation in a better way. Another research id also needed to develop method with respect to the requisite of the education or training.

\section{ACKNOWLEDGE}

The author are grateful to Educational Fund Management Institution (LPDP), Ministry of Finance of Republic Indonesia which funded this research, Rector of Universitas Airlangga and last but not least all ICU Nurses from Soetomo General Hospital, Universitas Airlangga Teaching Hospital, and The Hajj General Hospital Surabaya, East Java Indonesia who participated to this study.

\section{REFERENCES}

Al-homayan, A. M. et al. (2013) 'Effects of Job Stress and Organizational Support on the Relationship between Job Demand Resources and Nurses ' Job Performance in Saudi Public Hospitals', Australian Journal of Basic and Applied Sciences, 7(10), pp. 719.

Amiyanti, L. (2000) Analysis Factors Related to Stress Among Staff Nurse at Emergency Unit, DR. Tjipto Mangukusumo National Hospital.

Andolhe, R. et al. (2016) 'Estresse, coping e burnout da Equipe de Enfermagem de Unidades de Terapia Intensiva: fatores associados', Journal of School of Nursing, 49(spe), pp. 58-64. doi: 10.1590/s0080623420150000700009.

Burtson, P. L. and Stichler, J. F. (2010) 'Nursing work environment and nurse caring: Relationship among motivational factors', Journal of Advanced Nursing, 66(8), pp. 1819-1831. doi: 10.1111/j.1365-2648.2010.05336.x.

Cavalheiro, A. M., Moura Junior, D. F. and Lopes, A. C. (2008) 'Stress in nurses working in intensive care units', Revista Latino-Americana de Enfermagem, 16(1), pp. 29-35. doi: 10.1590/S010411692008000100005.

Desima, R. (2013) 'Tingkat Stres Kerja Perawat dengan Perilaku Caring Perawat', Jurnal Keperawatan, 4(1), pp. 43-55. doi: https://doi.org/10.22219/jk.v4i1.2380

Eisenberger, R. and Huntington, R. (1996) 'Perceived Organisational Support', Journal of Applied Psychology, 71(3), pp. 500-5007. doi: 10.1037//0021-9010.87.4.698

Jaafarpour, M., Khani, A. and Mahmodian, M. R. (2015) 'Evaluation of the quality of nursing work life and its association with job burnout in Isfahan University of Medical Sciences', International Journal of Epidemiologic Research, 2(1), pp. 30-39. Johan, S., Sarwar, H. and Majeed, I. (2017) 'To Identify the Causes of Stress among Nurses Working in Intensive Care Unit of Ittefaq Hospital Lahore', International Journal of Social Sciences and Management, 4(2), pp. 96-109. doi: 10.3126/ijssm.v4i2.17159.

Mariani, B. U. (2013) 'Faktor-Faktor Personal Sebagai Prediktor Terhadap Resiliensi Perawat Di Rumah Sakit Penyakit Infeksi', Journal of Infectious Disease, 1(1), pp. 14-21. doi: OI 10.32667/ijid.v1i01.3

Mealer, M. et al. (2012) 'The presence of resilience is associated with a healthier psychological profile in intensive care unit (ICU) nurses: Results of a national survey', International Journal of Nursing Studies, 49(3), pp. 292-299. doi: 10.1016/j.ijnurstu.2011.09.015.

Mealer, M. et al. (2018) 'Designing a Resilience Program for Critical Care Nurses', Advanced Critical Care Nursing, 28(4), pp. 359-365. doi: 10.4037/aacnacc2017252.Designing.

Nursalam (2015) Metodologi Penelitian Ilmu Keperawatan: Pendekatan Praktis. 5th edn. Jakarta: Salemba Medika.

Roshangar, F. et al. (2017) 'Job Stress and Quality of Nurse's work life', Pharmacophore, 8(6S), pp. 1-8.

Sarafis, P. et al. (2016) 'The impact of occupational stress on nurses ' caring behaviors and their health related quality of life', BMC Nursing. BMC Nursing, 15(56), pp.1-9. doi: 10.1186/s12912-016-0178-y. Siffleet, J. et al. (2015) 'Delivering best care and maintaining emotional wellbeing in the intensive care unit : the perspective of experienced nurses', Applied Nursing Research, 28, pp. 305-310. doi: 10.1016/j.apnr.2015.02.008.

Vahedian-azimi, A. et al. (2017) 'Effects of Stress on Critical Care Nurses: A National Cross-Sectional Study', Journal of Intensive care Medicine, $\mathrm{XX}(\mathrm{X})$, pp. 1-12. doi: 10.1177/0885066617696853.

Zaher, S. J., Vafaei, M. and Abianeh, E. E. (2016) 'Comparing Depression, Anxiety and Stress among theNurses in the Critical care and Internal Surgical units at the Selected Hospitals of the Social Security Organization of Tehran in 2016', International Journal of Medical Research \& Health Sciences, 5(9S), pp. 254-261.

Zhang, X., Huang, D. and Guan, P. (2014) 'Job burnout among critical care nurses from 14 adult intensive care units in northeastern China : a cross-sectional survey', BMJ Open, 3(e004813). doi: 10.1136/bmjopen-2014-004813. 